\title{
Correction to: Global Survey of Perceptions of the Surgical Safety Checklist Among Medical Students, Trainees, and Early Career Providers
}

\author{
Nikhil Panda ${ }^{1,2} \cdot$ Luca Koritsanszky $^{2,3} \cdot$ Megan Delisle $^{2,4} \cdot$ Theophilus T. K. Anyomih $^{5}$ • \\ Eesha V. Desai ${ }^{2}$ - Yves Sonnay ${ }^{2}$ George Molina ${ }^{1,2,6} \cdot$ Katayoun Madani $^{7,8,9}$. \\ Dominique Vervoort $^{7,10} \cdot$ Thomas G. Weiser $^{2,3,11} \cdot$ Evan M. Benjamin $^{2} \cdot$ Alex B. Haynes $^{2,12}$
}

Published online: 28 April 2020

(C) Société Internationale de Chirurgie 2020

\section{Correction to: \\ World J Surg \\ https://doi.org/10.1007/s00268-020-05518-x}

In the original version of the article, Dominique Vervoort's last name was misspelled. It is correct as reflected here. The original article has been updated.
Publisher's Note Springer Nature remains neutral with regard to jurisdictional claims in published maps and institutional affiliations.
The original article can be found online at https://doi.org/10.1007/ s00268-020-05518-x.

\section{Nikhil Panda}

nikhil.panda@mgh.harvard.edu

1 Department of Surgery, Massachusetts General Hospital, 55 Fruit Street, GRB-425, Boston, MA 02114, USA

2 Ariadne Labs, Harvard T.H. Chan School of Public Health, Brigham and Women's Hospital, 401 Park Drive, 3rd Floor West, Boston, MA 02215, USA

3 Lifebox Foundation, 48 Charlotte Street, London W1T 2NS, UK

4 Department of Surgery, University of Manitoba, 347-825 Sherbrook Street, Winnipeg, MB R3T 2N2, Canada

5 Department of Surgery, Tamale Teaching Hospital, P.O. Box TL111, Tamale, Ghana

6 Department of Surgery, Brigham and Women's Hospital, 75 Francis Street, Boston, MA 02215, USA
International Student Surgical Network (InciSioN), Sint-Truiden, Belgium

8 Saint George's University School of Medicine, 3500 Sunrise Highway, Great River, New York 11739, USA

9 Northwestern Trauma and Surgical Initiative, Arkes Family Pavilion (Suite 650), 676 North Saint Clair, Chicago, IL 60611, USA

10 Johns Hopkins Bloomberg School of Public Health, 615 North Wolfe Street, Baltimore, MD 21205, USA

11 Department of Surgery, Stanford Medicine, 300 Pasteur Drive, H3638, Stanford, CA 94305, USA

12 Department of Surgery and Perioperative Care, Dell Medical School, The University of Texas at Austin, 2601 Trinity Street, Building B, Austin, TX 78712, USA 